\title{
Congenital anophthalmia and microphthalmia: epidemiology and orbitofacial rehabilitation
}

This article was published in the following Dove Press journal:

Clinical Ophthalmology

I3 December 201 I

Number of times this article has been viewed

\author{
Sara Llorente-González' \\ J Peralta-Calvo 2 \\ JM Abelairas-Gómez ${ }^{2}$ \\ 'Ophthalmology Service of \\ Hospital de Torrejón, Madrid, Spain; \\ ${ }^{2}$ Ophthalmology Service of Hospital \\ Universitario La Paz, Madrid, Spain
}

Correspondence: Sara Llorente-González Ophthalmology Service, Hospital de Torrejón, Madrid, Calle Mateo Inurria, s/n, 28850 Torrejón de Ardoz, Madrid, Spain $\mathrm{Tel}+34914886624$

$\mathrm{Fax}+34988431682$

Email sarallog@gmail.com
Objective: To describe the prevalence of congenital anophthalmia and microphthalmia in Hospital Universitario La Paz, and to identify associated risk factors and evaluate cosmetic results in treated and nontreated patients.

Methods: A retrospective, descriptive, cross-sectional study of patients treated with orbital expanding techniques (cases) and nontreated patients (controls) was carried out as a comparative case series study. A total of 36 patients with unilateral or bilateral anophthalmia or microphthalmia as main diagnosis were included; 52 epidemiological and management variables for each patient were analyzed. The study evaluated orbital growth and facial symmetry.

Results: The overall cosmetic result in the study's group of patients was satisfactory: $66.7 \%$ showed good or very good orbital growth, and $75 \%$ showed good or very good facial symmetry. Controls had better cosmetic outcome but showed more cataracts $(P=0.05)$, inferior colobomas $(P=0.026)$, and family history $(P=0.056)$ than the cases. Controls also showed significantly better orbital growth $(P=0.042)$ and facial symmetry $(P=0.014)$ than the cases.

Conclusion: This study suggests that the mere presence of a globe (controls) still provides better orbitofacial development than the artificial stimulation (cases) currently available for patients with congenital anophthalmia and microphthalmia, who receive internal and external orbital rehabilitation.

Keywords: cosmetic outcome, orbital rehabilitation, ocular malformation, congenital cataract, persistent fetal vasculature

\section{Introduction}

Congenital anophthalmia and microphthalmia are rare diseases that cause deficient orbitofacial growth and impaired visual capability. Congenital anophthalmia is the complete absence of the eye due to deficient formation of the optic vesicle during early phases of gestation, while microphthalmia refers to the presence of a hypoplastic or rudimentary eye at birth. Ocular abnormalities in the development of the eye and its adnexal tissues include a wide range of malformations (anophthalmia, synophthalmia or cyclopia, congenital cystic eye, cystic microphthalmia, and microphthalmia with cystic teratoma), depending on embryonic age at onset of the disease. ${ }^{1-7}$ Microphthalmia may also manifest as a focal ocular malformation, such as congenital cataract or persistent fetal vasculature (PFV), instead of a generalized defect of ocular development.

The prevalence of anophthalmia and microphthalmia has been estimated at $0.2-3.0$ per 10,000 births. ${ }^{1-4,6,8}$ This severely limits the number of patients included in studies and makes it very difficult to find reliable epidemiological data. 
Cases associated to other congenital systemic abnormalities have been reported, and both conditions occur in many syndromes; for example, Fraser, Fryns, Waardenburg, or Matthew-Wood. ${ }^{9-14}$

A number of possible risk factors have been studied without apparent associations being found: maternal and gestational variables, patient characteristics, genetic alterations, and environmental factors or drugs during the gestational period. ${ }^{1,2,7,16-19}$

The absence of a normal-sized globe not only means orbital cavity and soft tissue growth retardation, but also leads to hemifacial microsomia affecting the development of the maxilla, maxillary sinus, and mandible.

Typically, severe congenital unilateral microphthalmia or anophthalmia produces bony orbital hypoplasia, microblepharon, and facial asymmetry due to hemifacial microsomia. In bilateral cases, the typical features are sunken orbits and midfacial hypoplasia. ${ }^{1-4,6}$

The diagnosis of anophthalmia or microphthalmia is clinical, obtained by ophthalmological examination demonstrating the complete absence of the globe or decreased ocular size relative to the contralateral eye. Once a diagnosis has been established, both ocular and systemic imaging tests (ultrasound, computed tomography [CT], and magnetic resonance imaging $[\mathrm{MRI}]$ ) should be performed to rule out neurological, renal, cardiac, or other associations. ${ }^{20}$

Treatment of microphthalmia depends on its severity and the visual potential of the affected eye, depending on etiology (eg, congenital cataract or PFV). Patients with mild microphthalmia are treated (eg, cataract surgery) for conditions that may arise, but are normally only subject to regular follow-up of orbitofacial growth stimulated by the presence of the globe (ie, "natural" stimulation), regardless of visual prognosis, unless this "natural stimulation" should prove to be insufficient. Patients with severe microphthalmia or anophthalmia, without potential vision, undergo early orbital rehabilitation with "artificial" stimulation of orbitofacial growth. Many clinicians begin with an external orbital conformer, useful per se, and to create a suitable access for a subsequent internal orbital conformer, if necessary.

Several techniques and materials (endogenous and exogenous) are used to expand orbital volume: serial acrylic conformers for conjunctival sac, conventional spherical orbital implants, mucous grafts, dermafat, bone and muscle grafts, inflatable balloon devices, and hemispherical and spherical self-inflating hydrophilic (hydrogel) expanders. . $^{-7,21-25}$

\section{Materials and methods}

The objectives of this study were to:

1. Describe the prevalence of congenital anophthalmia and microphthalmia treated at Hospital Universitario La Paz;

2 . Identify risk factors associated with congenital anophthalmia and microphthalmia; and

3. Evaluate cosmetic results in patients treated with orbital expanding procedures (cases) and nontreated patients (controls).

From the admission date of the first patient in April 1993 until June 2007, a total of 36 patients from the Paediatric Ophthalmology Department, Hospital Universitario La Paz, were included in the study. The inclusion criterion was unilateral or bilateral anophthalmia or microphthalmia as the initial diagnosis (Table 1).

The sample size $(n=36)$ in the present study refers strictly to patients and not to the total number of affected eyes $(n=50)$. In patients where both eyes were affected, focus was on the most affected eye, susceptible to interventional procedures, in order to avoid data sampling bias (Figure 1).

In spite of the different geographic origins of these children, minimum follow-up was 6 months (mean follow-up was $76.5 \pm 57.8$ months).

A total of 52 epidemiological and management variables were collected for each patient:

- Epidemiological variables (Table 2): current age, follow-up time, gender, chief complaint, unilateral/ bilateral, left/right eye (when unilateral), diagnosis, gestational anomalies, plurality (singleton, multiple), delivery (vaginal, forceps assisted, cesarean), parity, parity order, geographical origin, maternal age, maternal race/ethnicity, maternal educational level $(<12$ or $>12$ years at an educational institution; this variable was considered as a sociocultural indicator: $<12$ years, low level; $>12$ years, high level), ultrasound diagnosis, MRI diagnosis, CT diagnosis, positive TORCH serology, positive hepatitis serology, genetic anomalies, diagnosis group (mild = mild and moderate microphthalmia; severe $=$ severe microphthalmia and anophthalmia), coloboma, PFV, cataract, neurological anomalies, systemic anomalies, family history, and potential vision.

- Management variables (Table 3): retinal detachment surgery, cataract surgery, external orbital conformer, canthotomy, tarsorrhaphy, conjunctival sac reconstruction, enucleation, internal orbital conformation, oral mucous membrane graft, calvarial bone graft, dermafat graft, self-inflating hydrophilic expanders, total number of surgeries, useful visual acuity (VA), orbital growth, 
facial symmetry, external prosthesis mobility, internal prosthesis mobility, implant infection, internal prosthesis exposure/extrusion, eyelid ptosis, contralateral eye pathology (when unilateral).

Variables such as orbital growth, facial symmetry and external or internal prosthesis mobility (Table 4) were evaluated by two independent observers in all patients (except one) and classified into four categories (very poor, poor, good, and very good). They were therefore considered semiquantitative variables.

The study population was then divided into two groups according to the variable "potential vision," which determined the surgical approach. Those patients with potential vision did not undergo orbital expansion treatment and were just clinically observed, in order to monitor orbitofacial and ocular development (functional, but not cosmetic, surgical procedures were permitted, eg, cataract surgery). These patients were considered "controls" $(\mathrm{n}=14)$.

Patients without potential vision ("cases," $\mathrm{n}=22$ ) underwent external and/or internal expansion surgery, according to degree of severity. The cases were then divided into less severe (microphthalmia) and more severe (severe microphthalmia and anophthalmia).

Eyes with an axial length of 15-17 mm were classified as having mild microphthalmia, $13-15 \mathrm{~mm}$ as moderate, and less than $13 \mathrm{~mm}$ as severe (Figure 1). Anophthalmia was considered the absence of a globe on imaging techniques.

Following the study protocol, orbital rehabilitation in the more severe cases began in the first 3 months of life, with primary external orbital conformers, except in two patients who needed a secondary internal orbital conformer. Obviously, those patients who needed primary internal orbital conformers (six cases with anophthalmia) were also treated with external conformers at the same time.

The study's purpose was to determine whether there were any epidemiological or cosmetically significant differences between groups with "natural" (controls) or "artificial" orbital growth stimulation (cases). Because of the heterogeneity of the groups and the retrospective nature of the study, this was not a case-control study but rather a case series study.

A Microsoft Excel database was created, and SPSS Statistics (v 11.0; IBM Corporation, Somers, NY) software, was used for data analysis. Chi-square test was used for qualitative variables and Student's $t$-test for quantitative variables. Fisher's exact test was used when $\mathrm{n}<5$. Differences with a $P$ value $<0.05$ were considered statistically significant, and a $P$ value between 0.05 and 0.10 was considered to indicate a tendency to significance.

\section{Results}

The Tables 1-4 and Figure 1 show a detailed description of the variables and the comparative statistical analyses for the whole population and the groups.

Gender distribution for the whole sample showed no clear predominance, although the percentage of males (56\%) was higher than females (44\%). When stratified by group, there was no gender difference in the group of cases, whereas in the group of controls there was a higher percentage of males $(64 \%)$, which was not statistically significant $(P=0.400)$. Other authors have also reported that gender is not a risk factor for the disease. ${ }^{1,2}$

Most patients showed unilateral involvement (61\%), with no left or right eye predominance $(50 \%$ right [OD] and 50\% left [OS], among unilateral). When stratified by group, this pattern did not change: $66 \%$ OS in unilateral controls and $61 \%$ OD in unilateral cases. These results are consistent with those of other published series. ${ }^{1-4}$

There was no significant association between group with respect to: maternal race/ethnicity $(P=0.241)$, geographic origin, genetic or gestational alterations, child neurologic or systemic alterations, contralateral eye pathologies (when unilateral), gestation, delivery $(P=0.343)$, and parity. These data are in agreement with those of other published series. ${ }^{1,2}$

Mean maternal age at birth was: $33 \pm 6.6$ years for the whole group $(\mathrm{n}=28), 35.4 \pm 5.2$ years in the group of controls $(n=10)$, and $31.3 \pm 7.3$ years in the group of cases $(n=14)$. These data suggest a tendency to significance $(P=0.1)$ for worse cosmetic prognosis in younger mothers of the cases. Maternal sociocultural level also showed a tendency to significance $(P=0.098)$ between groups. Neither of these two variables has previously been considered as a risk factor in the literature. ${ }^{1,2}$

In all patients, prenatal obstetric ultrasound was unremarkable; diagnosis was therefore made at the time of birth $(n=34)$,

Table I Chief complaint $(\mathrm{N}=36)$

\begin{tabular}{ll}
\hline Chief complaint & Number of patients \\
\hline Bilateral anophthalmia & 4 \\
OD anophthalmia & 2 \\
OD anophthalmia + OS microphthalmia & 3 \\
OS anophthalmia & 3 \\
OS anophthalmia + OD microphthalmia & 1 \\
Bilateral microphthalmia & 6 \\
OD microphthalmia & 8 \\
OS microphthalmia & 9
\end{tabular}

Abbreviations: OD, right; OS, left. 
Table 2 Main epidemiological characteristics and possible risk factors

\begin{tabular}{llll}
\hline Variable & Global $(\mathbf{N})$ & Number of controls & Number of cases \\
\hline Maternal educational level & $>$ I2 years $(16)$ & 9 & 7 \\
$(\mathrm{~N}=28) ; P=0.098$ & $<12$ years $(12)$ & 3 & 9 \\
Associated ocular pathology & Cataract (3); $P=0.05$ & 3 & 0 \\
$(\mathrm{~N}=36)$ & $\mathrm{PFV}(9) ; P=0.267$ & 5 & 4 \\
& Inferior coloboma $(10) ; P=0.026$ & 7 & 3 \\
Pathologic associations & Family history $(\mathrm{N}=31) ; P=0.056$ & 6 & 3 \\
& Systemic alterations & 3 & 4 \\
& $(\mathrm{~N}=36) ; P=1.000$ & & 3 \\
& Neurologic alterations & 1 & 1 \\
& $(\mathrm{~N}=36) ; P=1.000$ & & 2 \\
& Contralateral eye involvement & & \\
\end{tabular}

Note: $P$-values are between groups.

Abbreviation: PFV, persistent fetal vasculature.

except in two patients with mild microphthalmia diagnosed several months after birth. Regarding diagnostic imaging techniques, ocular ultrasound was used most frequently $(\mathrm{n}=25)$, followed by MRI $(\mathrm{n}=11)$ and CT scan $(\mathrm{n}=8)$.

Karyotype test was performed in 13 patients, three of whom showed some minor genetic alterations with no systemic or syndromic anomalies.

Cosmetic outcomes (Table 4) between cases and controls were compared, grouping the four categories into two: satisfactory outcome (good and very good) and unsatisfactory outcome (poor and very poor). This allowed a comparison of larger samples.

\section{Discussion}

Given the low prevalence of congenital anophthalmia and microphthalmia, which varies widely in reported series, the authors of this present paper believe that the sample size was adequate ( $\mathrm{n}=36$ patients), in comparison with that of other studies: surgical series reported by Krastinova $(\mathrm{n}=19)$ and Schittkowski $(\mathrm{n}=13)$, and epidemiological series by Shaw $(\mathrm{n}=100)$ and Forrester $(\mathrm{n}=96) ., 1,2,4,24$

There was a statistically significant association in the group of controls with cataracts $(P=0.05)$ and inferior chorioretinal coloboma $(P=0.026)$. This circumstance could be explained by the fact that these focal ocular

Table 3 Therapeutic management and complications

\begin{tabular}{|c|c|c|c|}
\hline Variable & Global (N) & Number of controls & Number of cases \\
\hline Functional treatments & Cataract surgery + PFV (8) & 8 & 0 \\
\hline$(\mathrm{N}=36) ; P=0.000$ & Retina surgery $(\mathrm{I})$ & I & 0 \\
\hline External rehabilitation & External conformer ${ }^{\mathrm{a}}(23)$ & I & 22 \\
\hline \multirow[t]{4}{*}{$(N=36)$} & $P=0.003$ & & \\
\hline & Canthotomy (6) & 0 & 6 \\
\hline & Conjunctival sac reconstruction (6) & 0 & 6 \\
\hline & Tarsorraphy (10) & 0 & 10 \\
\hline Internal rehabilitation & Enucleation (8) & 0 & 8 \\
\hline \multirow[t]{6}{*}{$(\mathrm{N}=36)$} & Internal prosthesis (9) & 0 & 9 \\
\hline & $P=0.006$ & & \\
\hline & Oral mucous graft (6) & 0 & 6 \\
\hline & Calvarial bone graft (2) & 0 & 2 \\
\hline & Dermafat graft (5) & 0 & 5 \\
\hline & Orbital expansion (3) & 0 & 3 \\
\hline \multirow[t]{4}{*}{ Complications } & Implant infection ( $\mathrm{N}=9)$ : (2) & 0 & 2 \\
\hline & Internal prosthesis exposure $(\mathrm{N}=9)$ : $(2)$ & 0 & 2 \\
\hline & Ptosis $(\mathrm{N}=36):(10)$ & 0 & 10 \\
\hline & $P=0.003$ & & \\
\hline
\end{tabular}

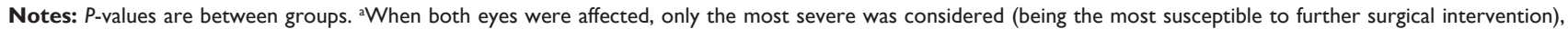
except for one patient with OS anophthalmia and OD microphthalmia with superior eyelid agenesis and acceptable vision. This patient was considered as a "control" because surgical procedures were performed on his best eye (OD), including application of a modified external conformer (in this variable, $n=23$ "cases"). Abbreviations: OD, right; OS, left; PFV, persistent fetal vasculature. 
Table 4 Cosmetic outcomes

\begin{tabular}{clll}
\hline Variable & Global & $\begin{array}{l}\text { Number } \\
\text { of controls }\end{array}$ & $\begin{array}{l}\text { Number } \\
\text { of cases }\end{array}$ \\
\hline Orbital growth & Very good $(\mathrm{N}=9)$ & 6 & 3 \\
$(\mathrm{~N}=36)$ & Good $(\mathrm{N}=15)$ & 7 & 8 \\
$\mathrm{P}=0.042$ & Poor $(\mathrm{N}=8)$ & $\mathrm{I}$ & 7 \\
& Very poor $(\mathrm{N}=4)$ & 0 & 4 \\
Facial symmetry & Very good $(\mathrm{N}=12)$ & 9 & 3 \\
$(\mathrm{~N}=36)$ & Good $(\mathrm{N}=15)$ & 4 & $1 \mathrm{I}$ \\
$\mathrm{P}=0.0 \mathrm{I4}$ & Poor $(\mathrm{N}=7)$ & $\mathrm{I}$ & 6 \\
& Very poor $(\mathrm{N}=2)$ & 0 & 2 \\
External mobility & Very good $(\mathrm{N}=0)$ & 0 & 0 \\
$(\mathrm{~N}=23)$ & Good $(\mathrm{N}=0)$ & 0 & 0 \\
& Poor $(\mathrm{N}=15)$ & $\mathrm{I}$ & 14 \\
& Very poor $(\mathrm{N}=8)$ & 0 & 8 \\
Internal mobility & Very good $(\mathrm{N}=0)$ & 0 & 0 \\
$(\mathrm{~N}=9)$ & Good $(\mathrm{N}=0)$ & 0 & 0 \\
& Poor $(\mathrm{N}=5)$ & 0 & 5 \\
& Very poor $(\mathrm{N}=4)$ & 0 & 4 \\
\hline
\end{tabular}

Note: $P$-values are between groups.

defects may have useful visual acuity and they produce mild microphthalmia.

In contrast to the cases, family history showed a tendency to significance in the group of controls $(P=0.056)$. Isolated microphthalmia has no known hereditary pattern, whereas congenital cataract is considered a hereditary pathology and was predominantly found in the control group. Obviously, when microphthalmia or anophthalmia are associated to Fraser, Fryns, Waardenburg, or Matthew-Wood syndromes, patients present well known hereditary genetic anomalies..$^{9-15}$

In this present study, no association with systemic or neurologic alterations or contralateral eye involvement (when unilateral) was found in the whole sample or in either of the two groups.
Ocular ultrasonography, which is noninvasive, readily available, and easy to perform, is useful in microphthalmia to assess axial length and intraocular conditions such as retinal detachment, posterior staphyloma, or retro-ocular cyst. Besides, it provides useful information in ocular growth follow-up.

CT and MRI are necessary to evaluate the presence of any ocular tissue in patients with clinical anophthalmia and the position and vascularization of orbital implants. ${ }^{20} \mathrm{MRI}$ is preferable in these patients because it is radiation-free and offers higher spatial resolution of soft tissues. However, CT best depicts the osseous orbital cavity.

In general, the patients in this study showed satisfactory cosmetic outcome: $66.7 \%$ had good or very good orbital growth, and $75 \%$ had good or very good facial symmetry. Better results for symmetry can be explained by the presence of bilateral involvement, where even with insufficient orbital growth, both sides of the face are similarly affected.

However, poor results were obtained for external conformer mobility (poor or very poor in $100 \%$ of cases, $n=23$ ) and internal implant mobility (poor or very poor in $100 \%$ of cases, $n=9$ ). A search of the literature found no specific percentages with which to compare these surgical results. Only isolated techniques for orbital rehabilitation or general surgical complications were found. ${ }^{4-6,24,25}$

When stratified by group, the controls achieved better orbital development than the cases, both in the four semiquantitative categories $(P=0.042)$ and when grouped into two categories (satisfactory outcome $=$ good and very good; unsatisfactory outcome $=$ poor and very poor $)(P=0.011)$. The group of controls also showed better facial symmetry ( $P=0.014$ in the four categories and $P=0.062$ in two).

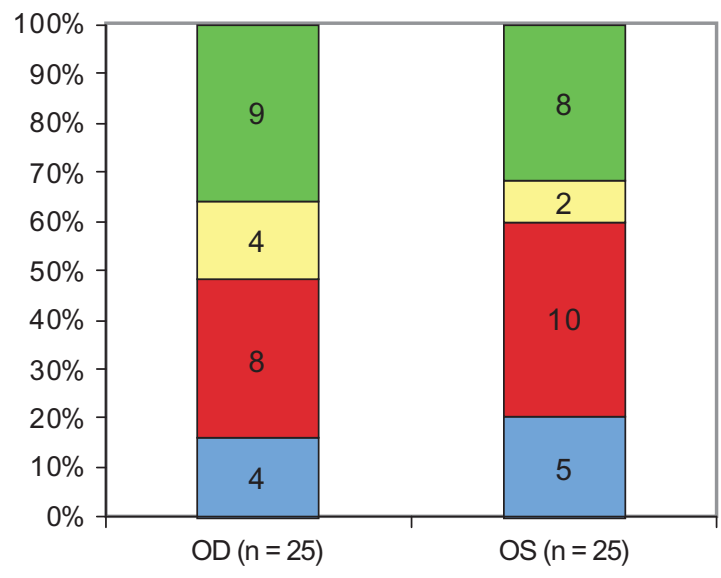

\begin{tabular}{|l|}
$\square$ Anophthalmia \\
$\square$ Severe microphthalmia $(<13 \mathrm{~mm})$ \\
$\square$ Moderate microphthalmia $(13-15 \mathrm{~mm})$ \\
$\square$ Mild microphthalmia $(15-17 \mathrm{~mm})$ \\
\hline
\end{tabular}

Figure I Diagnosis at baseline ( $\mathrm{n}=50$ affected eyes). Abbreviations: OD, right; OS, left. 
Surgical complications that commonly require further intervention include: cicatricial retraction of the conjunctival sac, exposure or extrusion of the internal implant, external conformer extrusion, infection, and obviously, insufficient orbital expansion. ${ }^{4,6,25}$ The complication rate was approximately $22 \%$ for infection and implant exposure/extrusion. Eyelid ptosis was found in $27.7 \%$ of the whole sample, all belonging to the group of cases $(P=0.003)$. It seems that the globe, even when microphthalmic, acts as a natural stimulus for orbital growth and preserves superior eyelid function. In contrast, external conformers are not always sufficient to achieve adequate superior and inferior conjunctival sac, and eyelid function is partially or totally abolished in some patients. Or, it may be that these patients had severe hypoplastic eyelid muscles (microblepharon) from baseline.

The present study suggests that natural stimulation of orbitofacial growth provided by a microphthalmic eye results in better outcome than artificial stimulation currently available with external and/or internal orbital conformers. These results are probably explained by the heterogeneous nature of the two groups, with higher associated pathology in the cases (micro-orbitism, microblepharon) and the baseline severity of the ocular disease itself. The possibility of other orbitofacial growth factors apart from the eye cannot be excluded and require further research.

Orbital rehabilitation in congenital anophthalmia and microphthalmia is a frustrating anatomical challenge for both parents and physicians. Every expansion technique has important limitations, and in some cases, despite several surgery procedures, patients do not achieve appropriate cosmetic outcome. It is encouraging to see satisfactory cosmetic outcomes in the cases (50\% for orbital growth and 63\% for facial symmetry) and the low rate of surgical complications.

The sample size was comparable with those of previous studies, especially the surgical series. However, larger sample sizes and longer follow-up periods are required in future studies. The results reported here allow us to persevere with the complicated task of orbitofacial rehabilitation of these patients.

\section{Disclosure}

The authors report no conflicts of interest in this work.

\section{References}

1. Shaw GM, Carmichael SL, Yang W, Harris JA, Finnell RH, Lammer EJ. Epidemiologic characteristics of anophthalmia and bilateral microphthalmia among 2.5 million births in California,1989-1997. Am J Med Genet A. 2005;137(1):36-40.

2. Forrester MB, Merz RD. Descriptive epidemiology of anophthalmia and microphthalmia, Hawaii,1986-2001. Birth Defects Res A Clin Mol Teratol. 2006;76(3):187-192.
3. Shah SP, Taylor AE, Sowden JC, et al. Anophthalmos, microphthalmos, and typical coloboma in the United Kingdom: a prospective study of incidence and risk. Invest Ophthalmol Vis Sci. 2011;52(1): 558-564.

4. Krastinova D, Kelly MB, Mihaylova M. Surgical management of the anophthalmic orbit, part 1: congenital. Plast Reconstr Surg. 2001;108(4):817-826.

5. Clauser L, Sarti E, Dallera V, Galiè M. Integrated reconstructive strategies for treating the anophthalmic orbit. J Craniomaxillofac Surg. 2004;32(5):279-290.

6. Mazzoli RA, Raymond WR 4th, Ainbinder DJ, Hansen EA. Use of self-expanding, hydrophilic osmotic expanders (hydrogel) in the reconstruction of congenital clinical anophthalmos. Curr Opin Ophthalmol. 2004;15(5):426-431.

7. Hayashi N, Repka MX, Ueno H, Iliff NT, Green WR. Congenital cystic eye: report of two cases and review of the literature. Surv Ophthalmol. 1999;44(2):173-179.

8. Aijaz S, Clark BJ, Williamson K, et al. Absence of SIX6 mutations in microphthalmia, anophthalmia, and coloboma. Invest Ophthalmol Vis Sci. 2004;45(11):3871-3876.

9. Amrith S, Lee Y, Lee J, Liew G, Leo S, Khoo B. Congenital orbitopalpebral cyst in a case of Fraser syndrome. Orbit. 2003;22(4): 279-283.

10. Pierson DM, Taboada E, Butler MG. Eye abnormalities in Fryns syndrome. Am J Med Genet A. 2004;125A(3):273-277.

11. Garavelli L, Pedori S, Dal Zotto R, et al. Anophthalmos with limb anomalies (Waardenburg opththalmo-acromelic syndrome): report of a new Italian case with renal anomaly and review. Genet Couns. 2006;17(4):449-455.

12. Makhoul IR, Soudack M, Kochavi O, Guilburd JN, Maimon S, GershoniBaruch R. Anophthalmia-plus syndrome: a clinical report and review of the literature. Am J Med Genet A. 2007;143(1):64-68.

13. Martinovic-Bouriel J, Bernabé-Dupont C, Golzio C, et al. Matthew-Wood syndrome: report of two new cases supporting autosomal recessive inheritance and exclusion of FGF10 and FGFR2. Am J Med Genet A. 2007;143(3):219-228.

14. Golzio C, Martinovic-Bouriel J, Thomas S, et al. Matthew-Wood syndrome is caused by truncating mutations in the retinol-binding protein receptor gene STRA6. Am J Hum Genet. 2007;80(6):1179-1187.

15. Chitayat D, Sroka H, Keating S, et al. The PDAC syndrome (pulmonary hypoplasia/agenesis, diaphragmatic hernia/eventration, anophthalmia/ microphthalmia, and cardiac defect) (Spear syndrome, Matthew-Wood syndrome): report of eight cases including a living child and further evidence for autosomal recessive inheritance. Am J Med Genet A. 2007;143A(12):1268-1281.

16. Schittkowski MP, Guthoff RF. Systemic and ophthalmological anomalies in congenital anophthalmic or microphthalmic patients. $\mathrm{Br} J$ Ophthalmol. 2010;94(4):487-493.

17. Vogt G, Puhó E, Czeizel AE. A population-based case-control study of isolated anophthalmia and microphthalmia. Eur J Epidemiol. 2005;20(11):939-946.

18. Sípek A, Gregor V, Horácek J, Masátová D. Birth defects' occurrence in offspring of mothers taking 1st trimester medication in the Czech Republic in 1996-2004. Ceska Gynekol. 2006;71(4):284-291. Czech.

19. Zenteno JC, Perez-Cano HJ, Aguinaga M. Anophthalmia-esophageal atresia syndrome caused by an SOX2 gene deletion in monozygotic twin brothers with markedly discordant phenotypes. Am J Med Genet A. 2006;140(18):1899-1903.

20. Ainbinder DJ, Haik BG, Mazzoli RA. Anophthalmic socket and orbital implants. Role of CT and MR imaging. Radiol Clin North Am. 1998;36(6):1133-1147, xi.

21. Agrawal PK, Kumar H. Microphthalmos with cyst: a clinical study. Indian J Ophthalmol. 1993;41(4):177-179.

22. Kitthaweesin K. Orbital aspiration as treatment of microphthalmos with orbital cyst: a case report. J Med Assoc Thai. 2002;85(9): 1024-1027. 
23. Brodsky MC. Congenital optic disk anomalies. Surv Ophthalmol. 1994;39(2):89-112.

24. Schittkowski MP, Gundlach KK, Guthoff RF. Treatment of congenital clinical anophthalmos with high hydrophilic hydrogel expanders. Ophthalmologe. 2003;100(7):525-534. German.
25. Schittkowski MP, Guthoff RF. Injectable self inflating hydrogel pellet expanders for the treatment of orbital volume deficiency in congenital microphthalmos: preliminary results with a new therapeutic approach. Br J Ophthalmol. 2006;90(9):1173-1177.

\section{Publish your work in this journal}

Clinical Ophthalmology is an international, peer-reviewed journal covering all subspecialties within ophthalmology. Key topics include: Optometry; Visual science; Pharmacology and drug therapy in eye diseases; Basic Sciences; Primary and Secondary eye care; Patien Safety and Quality of Care Improvements. This journal is indexed on

Submit your manuscript here: http://www.dovepress.com/clinical-ophthalmology-journal
Dovepress

PubMed Central and CAS, and is the official journal of The Society of Clinical Ophthalmology (SCO). The manuscript management system is completely online and includes a very quick and fair peer-review system, which is all easy to use. Visit http://www.dovepress.com/ testimonials.php to read real quotes from published authors. 